\title{
An update from the business meeting in Melbourne
}

On 19 February 1996 more than 50 members of the International Society for Child and Adolescent Injury Prevention met in Melbourne. The meeting was chaired by Fred Rivara, MD, MPH.

\section{President's report}

Angela Seay was hired to staff ISCAIP at CAPT headquarters in London on a part time basis and her services have proved invaluable to the executive. Major accomplishments: (1) Injury Prevention was launched and has nearly reached its targeted goal of subscribers for the first year. Its success is due to the hard work of many. Congratulations and thanks were offered to the editor and to Alex Williamson at the BMJ Publishing Group. (2) A membership directory has been published to facilitate collaboration and exchange among ISCAIP members and with other injury prevention practitioners. It includes details about all 138 members who responded to a survey. Members not in attendance will receive it in the mail. (3) In conjunction with Kidsafe Australia the society sponsored a special afternoon session after the close of the Third International Conference. Over 120 people attended. The program included reports from Africa, Europe, Asia, the Americas, and Australia/New Zealand; a discussion on interdisciplinary efforts led by Terry Nolan, and another on funding. (4) An attractive membership brochure is now available, as is letterhead stationery.

\section{Treasurer's report}

Based only on membership dues the society is solvent. The main expenses include the salary for Angela Seay, printing costs, routine office supplies, marketing efforts, and conference costs. The afternoon session (above) will produce a profit of about $£ 900$. Despite having more than 140 dues-paying members, ISCAIP cannot be in the forefront of child injury prevention internationally. Several suggested ways to increasing membership. All were asked to make a major effort to recruit one new member this year. (Contact Mike Hayes directly for a more detailed financial statement.)

\section{Proposed activities}

Several ideas were presented by the President for general discussion: (1) Develop an Listserver for members only. (2) Serve as a repository of information on prevention programs by developing a World Wide Website. (3) Conduct a comprehensive survey of child injury prevention programs underway across the world. (4) Conduct a systematic review of the effectiveness of various prevention strategies using a Cochrane-like critical review process. A lively discussion followed and given space constraints, what follows is a summary of these comments.

\section{List serve/WWW}

More than $90 \%$ indicated they have e-mail and access to the WWW. It was suggested it may be better to develop an enhanced web site for ISCAIP, with password limited access. Although this must be kept up-to-date, it requires less maintenance than a Listserver. Liz Towner has applied for funding to get additional literature review updates on the Web and offered to work on this if we decided to pursue a Web site. Other ideas for the use of a Web site were to improve collaboration and networking; to summarize work in progress; to maintain a log of funded projects; to coordinate information on childhood injuries and severity measures. Keeping a Web site up-to-date requires time and energy and criteria to decide what is to be included. No final decision was reached.

\section{International inventory}

This would be similar to a state by state survey completed several years ago by Susan Gallagher. Although it might be difficult to keep the results up-to-date or to find funds to repeat it in the future, its benefits include increased visibility for the society, which in turn, could increase membership. It would identify contacts in countries not yet represented and enable us to learn more about the needs of the field throughout the world. A proposal has been submitted to one foundation and other funding sources are being researched. A copy of the exploratory funding letter has been provided to the Executive Board for use in contacting potential funders regarding the project.

\section{Cochrane collaboration}

A systematic survey of the extent to which child injury prevention programs have been effective would be of great value. It was proposed that we should seek approval for an injury oriented Cochrane Collaboration so that the work could be completed before the Amsterdam meeting. This was discussed further at the Thursday session, and a request for support has been submitted to a foundation by Fred Rivara. Additional throughts on these activities should be communicated to Angela Seay by e-mail at 100545.3625@compuserve.com or by snail mail to CAPT in London. If you are on e-mail and were not at the meeting, let Angela know so that you can be added to her list for future communication.

\section{Funding}

Dues may keep up with our core administrative activities, but more money is needed to undertake special projects. Apart from the initiatives described above, ISCAIP approached a bike helmet company for assistance with core expenses, but was unsuccessful. Other possibilities include approaching Unicef; commercial firms like Toys-'R'-Us; the European Consumer Union; other foundations; hiring a firm to help us; demonstrating in-kind services being done by ISCAIP members to illustrate our commitment; marketing a training and education service; making a connection with one of the computer software/hardware firms; or finding an international company to be our benefactor. It was also suggested that we define ethical principles for inclusion in the bylaws and that the use of child labor that may contribute to the injury problem be considered when considering firms to approach. 


\section{Election of officers}

The current composition of the ISCAIP Executive Board consists of three elected officers: President, Fred Rivara; Treasurer, Mike Hayes; and Secretary, Sue Gallagher, as well as up to five at-large members from Australia and New Zealand (Ian Scott), Europe (Wim Rogmans), Asia (vacant), Africa (vacant), and North/South America (vacant). The term of the currently elected ISCAIP officers expired on February 29th. A discussion of the election nomination process, the length of terms for office, the need for a chair-elect, and the need for more specific bylaws, ensued. Staggered, overlapping terms were proposed. There was also concern that we build in the capacity to maintain a relationship with the $B M \mathcal{F}$, our journal sponsor, and with CAPT, where our secretariat lies. A solicitation for nominations and revisited bylaws will be sent out shortly. Those with an e-mail address will receive it electronically; those without by regular post. This will be followed by a ballot to elect the board, which will, in turn, elect officers. A vote of confidence and thanks was given to our current President, Fred Rivara.

\section{International conference in Amsterdam}

We discussed getting involved early on with the planning of the Fourth International Conference on Injury Prevention and Control to be held in Amsterdam in May 1998. In the interests of promoting cross fertilization, the Australian conference did not have an age group orientation. Childhood injury prevention was interspersed among a variety of sessions. To ensure that sessions of relevance to ISCAIP members are planned, Mike Hayes will keep in touch with Wim Rogmans concerning the Amsterdam conference. Our goals are to have a major plenary on childhood injury, to group other childhood sessions, and to have a separate ISCAIP meeting.

\section{Other}

The need for developing consensus recommendations in areas such as the definition of pediatric injury severity was suggested as a future activity. Another issue was how to gain greater visibility and be accepted as a resource for global injury control activities so that, for example, WHO and others will seek our input. Special thanks were expressed to Ian Scott for making the arrangements for 65 of us to dine together after the business meeting.

\section{SUSAN SCAVO GALLAGHER}

Secretary, ISCAIP

Center for Injury and Violence Prevention and

Children's Safety Network,

Education Development Center Inc,

55 Chapel Street, Newton,

$M A$ 02158-1060, USA

Where do the guns come from?

The tragic mass killing of 16 children in Dunblane, Scotland in March once again focuses the spotlight on the part played by the availability of guns. Although many argue that disturbed persons will always be a threat, others counter that this is precisely the reason why restricting the availability of weapons is so important. Our deepest sympathies go to the families, their friends, and the entire community.

New AAAM President from France

For the second time in its 40 year history, the American Association for Automotive Medicine (AAAM) has elected a non-American to be its president - Dr D Cesari, head of the Crash Protection and Biomechanics Laboratory in Lyon, France. The laboratory is a research unit of INRETS (the French National Institute for Research in Transport Safety).

\section{Support for red light cameras}

On average, at least in one US community studied, there is a red light violation every 12 minutes, amounting to an average of 126 per day. Encouragingly, two new surveys by the Insurance Institute for Highway Safety reveal that $66 \%$ favor using red light cameras that automatically photograph the rear license plates of vehicles that run red lights to help reduce this problem. Added to the basic problem is that violaters tend to do so at speed: $16 \%$ were going $55 \mathrm{mph}$ or faster in a $45 \mathrm{mph}$ zone. 